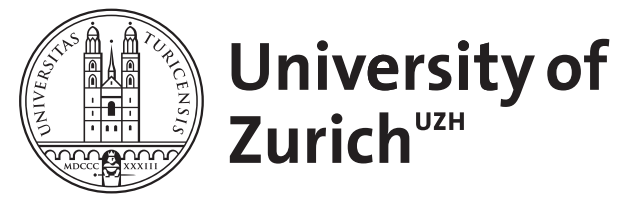

No superoxide dismutase activity of cellular prion protein in vivo

Hutter, G ; Heppner, F L ; Aguzzi, A

DOI: https://doi.org/10.1515/BC.2003.142

Posted at the Zurich Open Repository and Archive, University of Zurich ZORA URL: https://doi.org/10.5167/uzh-1887

Journal Article

Published Version

Originally published at:

Hutter, G; Heppner, F L; Aguzzi, A (2003). No superoxide dismutase activity of cellular prion protein in vivo. Biological Chemistry, 384(9):1279-1285.

DOI: https://doi.org/10.1515/BC.2003.142 


\section{No Superoxide Dismutase Activity of Cellular Prion Protein in vivo}

\author{
Gregor Huttera, Frank L. Heppnera,^ and \\ Adriano Aguzzi*
}

Institute of Neuropathology, Schmelzbergstrasse 12, University Hospital of Zürich, CH-8091 Zürich,

Switzerland

${ }^{*}$ Corresponding authors

Prion diseases are characterized by the deposition of PrPsc, an abnormal form of the cellular prion protein PrPc, which is encoded by the Prnp gene. PrPc is highly expressed on neurons and its function is unknown. Recombinant PrPc was claimed to possess superoxide dismutase (SOD) activity, and it was hypothesized that abrogation of this function may contribute to neurodegeneration in prion diseases. We tested this hypothesis in vivo by studying copper/zinc and manganese SOD activity in genetically defined crosses of mice lacking the Sod1 gene with mice lacking PrPc, and with hemizygous or homozygous tga20 transgenic mice overexpressing various levels of PrPc. We failed to detect any influence of the Prnp genotype and gene dosage on SOD1 or SOD2 activity in heart, spleen, brain, and synaptosome-enriched brain fractions. Control experiments included crosses of mice lacking or overexpressing $\operatorname{PrPC}^{\mathrm{C}}$ with mice overexpressing human $\mathrm{Cu}^{2+} / \mathbf{Z n}^{2+-}$ superoxide dismutase, and confirmed that SOD enzymatic activity correlated exclusively with the gene dosage of bona fide human or murine SOD. We conclude that PrPc in vivo does not discernibly contribute to total SOD activity and does not possess an intrinsic dismutase activity. Key words: Prion disease/PrPc/SOD/Synaptosomes / Transgenic mice.

\section{Introduction}

Prion diseases are lethal neurodegenerative disorders that affect humans and a variety of animal species. They include bovine spongiform encephalopathy (BSE) in cattle, chronic wasting disease in mule deer and elk, and Creutzfeldt-Jakob disease (CJD) in humans. The causative agent is termed prion (Prusiner, 1982) and was proposed to be identical with PrPsc, a pathological conformer of the cellular protein PrPc encoded by the Prnp gene (Oesch et al., 1985; Basler et al., 1986). PrPC is a glycosyl-phosphatidylinositol (GPI)-anchored glycopro-

\footnotetext{
a These authors contributed equally to this study.
}

tein expressed on the surface of almost all cells in the body, but at particularly high levels on neurons. PrPc has been shown to be essential for the development of prion disease, and Prnp ${ }^{\circ / 0}$ mice, which lack $\mathrm{PrP}^{\mathrm{C}}$, are resistant to scrapie (Büeler et al., 1993).

The physiological function of $\mathrm{PrPc}$ is unknown, and may be linked to prion pathophysiology. If $\mathrm{PrP}^{\mathrm{C}}$ was an enzyme, one could speculate that conversion to PrPsc may trigger changes in its activity or substrate specificity, which - by a loss-of-function or gain-of-function - may conceivably contribute to prion pathology. The latter line of thought gained considerable momentum when it was shown that synthetic peptides encompassing the octarepeat region of $\mathrm{PrPC}^{\mathrm{C}}$ bind copper (Hornshaw et al., 1995) and a $\mathrm{PrP}^{\mathrm{C}}$-copper complex was also described in vivo (Brown et al., 1997a; Stockel et al., 1998).

$\mathrm{PrP}^{\mathrm{C}}$ was hypothesized to act as an antioxidant (Brown et al., 1999; Sayre et al., 1999; Wong et al., 1999), since cultured cells lacking $\mathrm{PrP}^{\mathrm{C}}$ were reported to display an altered response to oxidative stress in vitro (Brown et al., 1997b, 1998) and in vivo (Klamt et al., 2001; Wong et al., 2001; Brown et al., 2002) and show a higher rate of apoptosis upon growth-factor withdrawal (Kuwahara et al., 1999). It was then reported that Prnpo/o mice exhibit decreased activity of the $\mathrm{Cu}^{2+} / \mathrm{Zn}^{2+}$-superoxide dismutase (SOD1; Brown et al., 1997b), a major radical scavenger enzyme located in the cytosol and other subcellular compartments (Kira et al., 2002). If this was correct, PrPc might contribute indirectly to SOD1 activity, or may be an SOD itself (Brown et al., 1999; Wong et al., 2000), whose reduced availability (thanks to conversion into $\mathrm{PrPsc}$ ) may reduce scavenging of reactive oxygen species and contribute to neurodegeneration in prion diseases.

The data discussed above may provide a simple and attractive theory of prion pathogenesis, but have been challenged in various ways. Firstly, the results favoring an SOD-like activity of $\mathrm{PrPc}$ were mainly generated with recombinant bacterially expressed proteins - which may or may not reproduce the activity of $\mathrm{PrPc}^{\mathrm{c}}$ in vivo. Secondly and more worryingly, Waggoner and colleagues found no correlation between brain copper content, level of PrPc expression, and cuproenzyme activity in mice overexpressing or lacking $\operatorname{PrPc}(2000)$. Thirdly, it is now established that unintentional overexpression of the PrPc-homologue $\mathrm{Dpl}$ in some $\mathrm{PrPC}^{\mathrm{C}}$-deficient mouse strains and cell lines accounts for at least some of the alterations described above (Moore et al., 1999; Behrens and Aguzzi, 2002).

The contradictory reports on whether PrPc exhibits SOD activity in vivo prompted us to analyze this question in defined genetic mouse models. Using two independ- 
ent assays, we were not able to detect any $\mathrm{PrP}^{\mathrm{C}}$-dependent modulation of SOD activity in heart, spleen, liver, brain as well as in synaptosome-enriched brain fractions. We conclude that a direct or indirect contribution of PrPc to SOD activity in these organs, at least under physiological conditions, appears to be unlikely.

\section{Results and Discussion}

The current study was undertaken to test whether PrPc modulates the total SOD activity in mouse tissues in vivo. Formally, PrPC may alter SOD activity, because (i) it possesses intrinsic dismutase activity, or (ii) because it modifies, directly or indirectly, the activity of the endogenous SOD1 enzyme - for example by altering copper metabolism. Finally (iii), PrPc may conceivably modify by unknown mechanisms, the activity and/or the tissue distribution of the mitochondrial SOD2 enzyme.

In order to prove or disprove each one of these hy- potheses in vivo, we determined SOD1 and SOD2 activities in various crosses of mice lacking the Prnp and/or Sod1 genes with mice transgenic for murine Prnp and for the human copper-zinc SOD, hSod1. Transgenic Sod1 1/-; Prnp $^{\circ / 0}$ and Sod1-/-;Prnpo/;ga20+/- or Sod1-/-;Prnpo/; tga20 ${ }^{+/+}$mice were obtained by intercrossing Sod ${ }^{-/-}$mice (Ho et al., 1998) with tga20 mice (Fischer et al., 1996) which overexpress PrPC (Figure 1A). For control experiments, we intercrossed transgenic mice overexpressing the human SOD1 gene, hSod1 (Epstein et al., 1987), with tga20 mice. Genotypes were screened by PCR analysis (Figure 1B-E) and confirmed by assessing the presence or absence of the proteins of interest by Western blot (SOD1, MnSOD, $\operatorname{PrPC}$ ), as well as functionally by analyzing SOD1 and SOD2 enzyme activity (Figure 2). Double and triple transgenic mice obtained in these crossings did not show obvious phenotypic alterations, except for mice homozygous for a disrupted SOD1 allele that exhibited reduced fertility, as described earlier (Ho et al., 1998). All mice developed normally, had a normal life expectan-
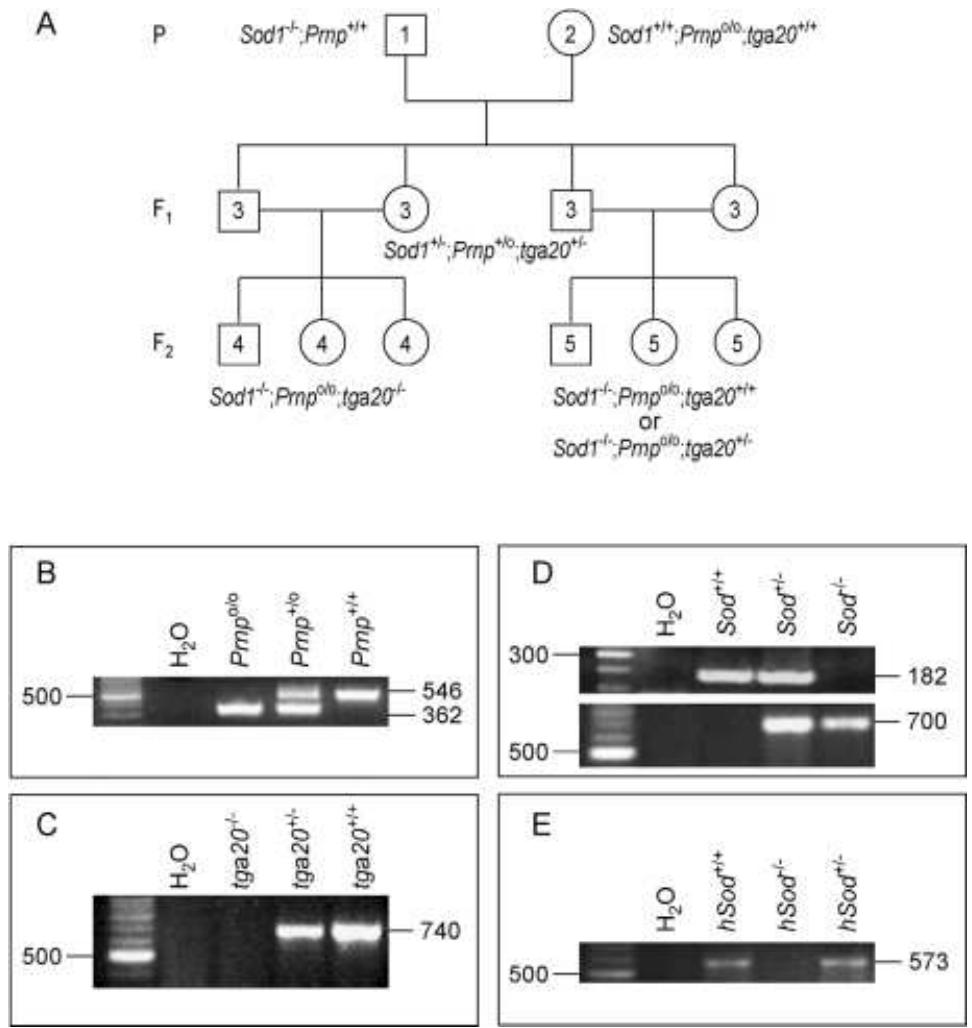

Fig. 1 Breeding Strategy Depicted by a Pedigree (A) and PCR-Based Mouse Genotyping (B-E).

(A) Mice lacking SOD while expressing wild-type levels of $\operatorname{PrPC}^{\circ}\left(\mathrm{Sod}^{-1-}\right.$; $\mathrm{Prnp}^{+/+}$; Ho et al., 1998) were intercrossed with tga20 mice that transgenically express PrPc under the control of the Prnp promoter on a Prnp-deficient background leading to an overexpression of $\mathrm{PrPC}$ in all tissues (Fischer et al., 1996) while displaying wild-type levels of SOD1 (Sod1+/+;Prnpo/\%;ga20+/+). The $\mathrm{F}_{1}$-generation was intercrossed with each other to obtain the indicated genotypes in the $F_{2}$-generation. (B) Mouse genotypes were identified by PCR analysis. The Prnp-status was revealed by a PCR using three primers within the same reaction (see Materials and Methods), resulting in a $362 \mathrm{bp}$ band for the neo-cassette and a larger 546 bp band for Prnp ${ }^{+}$. (C) Specific primers were used for detecting the tga20 transgene resulting in a $740 \mathrm{bp}$ band. (D) Presence of the Sod ${ }^{+}$wild-type allele was confirmed by a $182 \mathrm{bp}$ band which is abolished in SOD1 $1^{--}$ mice. The Sod ${ }^{-}$allele was demonstrated by an amplicon of 770 bp displaying the exon 4/neo cassette of the targeted Sod1-locus, whereas in (E) the human $h S o d 1$ transgene was revealed by a band of $573 \mathrm{bp}$. (B-E) Respective genotypes of mice are indicated and a 100 bp DNA ladder (Boehringer, Rotkreuz, Switzerland) is shown on the left. Numbers on the right indicate respective size of the PCR amplicons. 
A

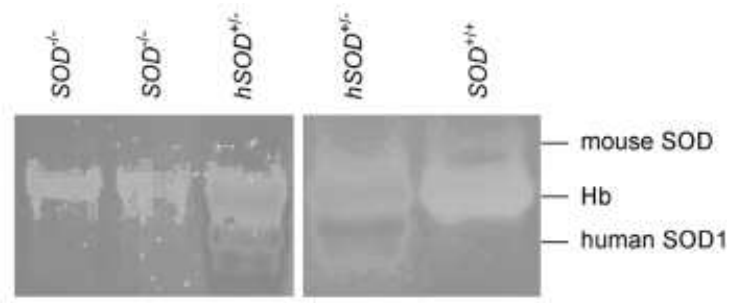

B

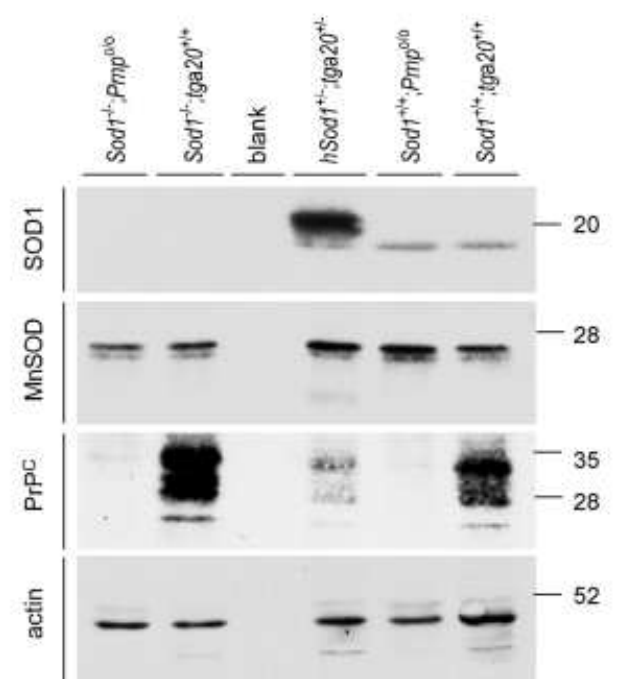

Fig. 2 SOD Activity in Peripheral Blood and Protein Expression in Spleen Homogenates.

(A) A non-denaturing gel-electrophoresis of peripheral blood was performed resulting in mouse/mouse homodimers (mouse $\mathrm{SOD})$ migrating above hemoglobin $(\mathrm{Hb})$, mouse/human heterodimers co-migrating with hemoglobin and a strong band of human homodimeric SOD1 (human SOD1) below hemoglobin in transgenic mice expressing hSOD1. Respective genotypes of mice are indicated. (B) Western blot analysis of spleen homogenates of various mouse genotypes, as indicated, revealing the expression, overexpression or absence of SOD1, MnSOD and $\mathrm{PrP}^{\mathrm{C}}$, as shown on the left. The human SOD1-band migrates slightly slower and exhibits a strong band due to its overexpression in transgenic hSod1 mice. Equal loading is demonstrated by developing membranes with an anti- $\beta$-actin antibody (lower panel). Molecular mass in $\mathrm{kDa}$ is indicated on the right.

cy ( $>350$ days at the time of writing) and did not show histological abnormalities in brain, spleen, liver, kidney and heart (data not shown).

Next, we evaluated SOD activity in brain, spleen, liver and heart of mice expressing varying amounts of $\mathrm{PrPC}$. Using the xanthine/xanthine oxidase formazan based SOD assay, we were not able to detect any difference in total SOD activity between brain homogenates of Prnpo/, wild-type, and tga20 mice which lack, express physiological amounts of, or overexpress $\mathrm{PrPC}^{\mathrm{C}}$, respectively (Figure 3A, B). These results are in line with those obtained by Waggoner and colleagues (2000). In addition, we were not able to detect any SOD activity other than SOD2 in mice overexpressing $\mathrm{PrPC}$ but lacking SOD1 (Sod $^{-/-;}$tga20 $\mathrm{O}^{+/-}$or Sod $\mathrm{S}^{-/-} ;$tga20 $\mathrm{O}^{+/+}$; Figure 3A-D). This indicates that $\mathrm{PrPC}$, even when expressed at supraphysio- logical levels, does not exhibit any intrinsic SOD activity in vivo. Similar results to those in brain (Figure 3A, B) were obtained in heart (Figure 3C, D), spleen (Figure 3E) and liver (data not shown), consistently and regardless of whether samples were analyzed in kinetic (Figure 3A, B, E) or endpoint mode (Figure 3C, D), in which decrease in the reaction speed or inhibition of formazan production are plotted, respectively.

Inhibition of SOD1 activity by KCN revealed no detectable levels of MnSOD in brain (Figure 3B), liver, and spleen of any of the mice investigated (data not shown) and confirmed the specificity of the assay. In contrast, MnSOD was readily detectable in mitochondria-rich heart homogenates and, similar to SOD1, appeared to be independent of PrPC-expression levels (Fig 3C, D). Multiple independent experiments and use of alternative homogenization buffers and procedures (0.5\% NP-40 and $0.5 \%$ DOC or sonication followed by ultracentrifugation at $78000 \mathrm{~g}$ for $30 \mathrm{~min}$ ) as described earlier (Ewing and Janero, 1995) produced the same results (data not shown). An additional, independent SOD assay based on auto-oxidation (Nebot et al., 1993) yielded identical results (Figure 3F). Repeated measurements confirmed that the latter assay was robust and highly reproducible with control material and all experimental samples (data not shown).

The highest concentration of $\mathrm{PrPc}$ is found in synaptosome-enriched subcellular fractions, leading to speculations that $\mathrm{PrP}^{\mathrm{C}}$ may serve as a copper buffer in the synaptic cleft (Brown et al., 1997a; Kretzschmar et al., 2000). We therefore assayed the SOD activity of synaptosomeenriched brain fractions of mice of all the genotypes described above. In order to confirm the presence of SOD1 and of $\mathrm{PrPC}^{\mathrm{C}}$ in crude synaptosomal brain fractions, aliquots of each sample were subjected to Western blot analysis in addition to SOD activity assays (Figure 4A). Again, and in flagrant contrast to other reports (Brown and Besinger, 1998; Brown et al., 1999; Milhavet et al., 2000; Wong et al., 2000; Brown et al., 2002; Klamt et al., 2001; Milhavet and Lehmann, 2002) we did not find any contribution of $\mathrm{PrPc}^{\mathrm{C}}$ to the overall SOD activity, nor did we detect any intrinsic SOD activity of $\mathrm{PrPC}^{\mathrm{C}}$ in crude synaptosomal brain fractions (Figure 4B).

Our results indicate that modulation of $\mathrm{PrPc}$ levels does not influence the SOD activity in a series of tissues, including brain. The data presented here were collected from organs of genetically defined mouse models lacking or expressing various levels of $\mathrm{PrPc}$ in the presence or absence of endogenous SOD1, whereas most data deposing in favor an SOD activity of $\mathrm{PrPc}$ were recorded with recombinant proteins. In addition, the xanthine-xanthine oxidase based assay (Okado-Matsumoto and Fridovich, 2001) used in this study may be more sensitive and less error-prone than the NBT-method mainly used in previous studies (Brown et al., 1997b, 1999; Brown and Besinger, 1998; Milhavet et al., 2000; Wong et al., 2000). The NBT assay was shown to potentially interfere with xanthine oxidase (Ukeda et al., 1997) and resulted in a 
A
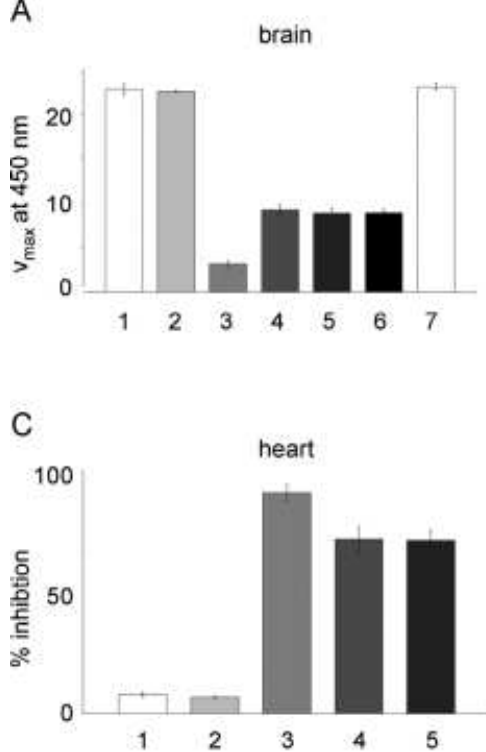

E

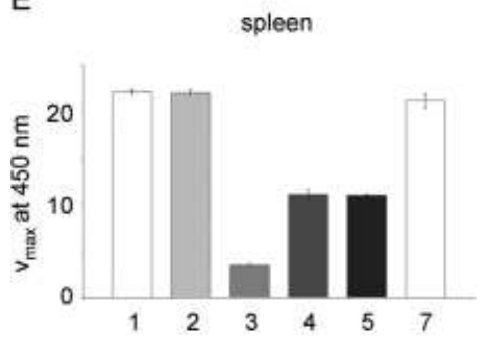

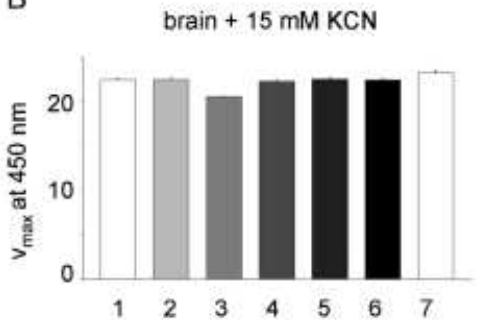

D

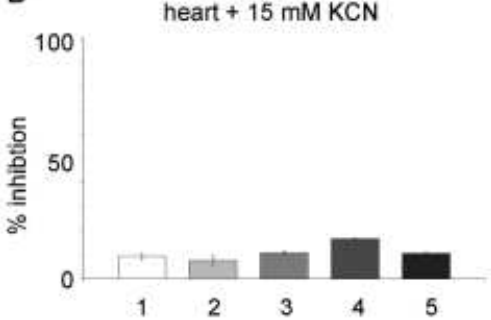

$\mathrm{F}$

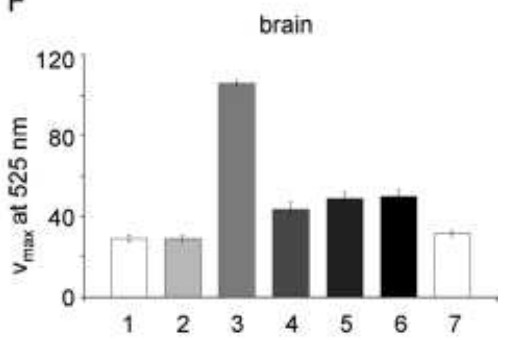

\begin{tabular}{|c|c|c|c|}
\hline 1: Sod1 $;$ Pmpolo & 3: $h$ Sodt $1^{+h} ; \operatorname{tga} 20^{4 f}$ & 5. Sod1 ${ }^{*+4} ; \operatorname{tga} 2 O^{4 / 4}$ & 7: blank \\
\hline 2. Soot $1^{+1}$ tga2 $0^{+1+}$ & 4: $\operatorname{Sod1}^{+1+} ; \mathrm{Pmp}^{\mathrm{ab}}$ & 6: $\mathrm{Sod1}^{+1+} \cdot \mathrm{Pmp}^{+1+}$ & \\
\hline
\end{tabular}

Fig. 3 SOD Activity in Brain, Spleen and Heart Homogenates.

(A) Kinetic measurement of WST-Formazan reduction in a xanthine-xanthine oxidase based SOD-assay at $450 \mathrm{~nm}$ over $30 \mathrm{~min}$ at $37^{\circ} \mathrm{C}$ displaying no significant difference in brain homogenates of mice lacking or overexpressing $\operatorname{PrPc}$ (lanes $4-6$ ). No significant SOD-activity was measurable in mice lacking SOD1 (lanes 1-2), even when PrPc was overexpressed (lane 2). As positive control mice overexpressing the human SOD1 (lane 3) were used yielding high SOD levels. (B) KCN-inhibition of same samples as in (A) resulting in a complete inhibition of SOD1, thus displaying MnSOD activity. While the MnSOD enzyme was present in brain extracts (see Figure 2B), its activity even on a SOD1-/-background (lanes 1-2) could not be detected in brain, spleen (not shown) and liver (not shown) samples. Merely a residual SOD1 activity in transgenic $h$ Sod 1 mice was detectable, since $15 \mathrm{~mm} \mathrm{KCN}$ were not sufficient to completely abolish human SOD1 overexpression. Values are indicated as $v_{\max }$ in $\mathrm{mOD} / \mathrm{min}$ in the linear range of the assay. (C) and (D) indicate percent inhibition of WST-Formazan reduction in a xanthine-xanthine oxidase based SOD-assay with an endpoint measurement at $450 \mathrm{~nm}$ in heart homogenates yielding similar results as in (A). In mitochondria-rich heart fractions, MnSOD is readily detectable upon adding $15 \mathrm{~mm} \mathrm{KCN} \mathrm{at}$ similar levels independent of the level of $\mathrm{PrPC}^{\mathrm{C}}$ expression. (E) Kinetic measurement of WST-formazan reduction in a xanthine-xanthine oxidase based SOD-assay in spleen homogenates also displays no contribution of PrPc to the SOD-activity (lanes 4 and 5) or an intrinsic SOD-like activity in the absence of SOD1 (lane 2 vs. 1). Again, mice overexpressing the human SOD1 (lane 3) served as positive control. (F) Similarly as in the formazan based assay (see 3A), no SOD-like activity of $\mathrm{PrPC}^{\mathrm{C}}$ in brain homogenates was detectable when a SOD-assay was used that is based on auto-oxidation. (A-F) Six different mouse genotypes are displayed in lanes 1-6. Lane 1: Sod1 1--;-Prnpo/\%,

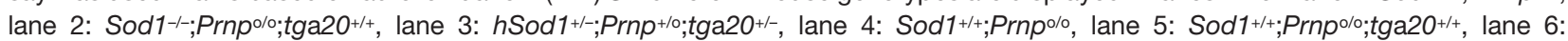
Sod $1^{+/+} ; P_{n n p^{+/+}}$, lane 7: water or buffer (blank). Several independent experiments were performed of which one representative is shown. Experiments were performed in triplicate and mean value \pm standard deviation is depicted.

poor reproducibility in our hands. While $\mathrm{PrPC}^{\mathrm{C}}$ or peptides thereof might exhibit a SOD1-mimetic function under rather artificial settings in vitro, our results indicate that in vivo a contribution of $\mathrm{PrPC}^{\mathrm{C}}$ to the SOD activity or a direct SOD-like function of $\mathrm{PrPC}$, at least under physiological conditions, appears to be unlikely. Certainly, it cannot be excluded that $\mathrm{PrPC}^{\mathrm{C}}$ merely under conditions of stress ex- hibits a SOD-like function and, consequently, abrogation of $\mathrm{PrP}^{\mathrm{C}}$, e.g. in the course of prion disease, where $\mathrm{PrP}^{\mathrm{C}}$ is converted into PrPsc, might be causally linked to increased free radical formation and thus accelerate neurodegeneration. This scenario, however, appears to be less likely, since SOD1-activity levels and SOD1 protein expression are not decreased in brains of scrapie-infect- 
A
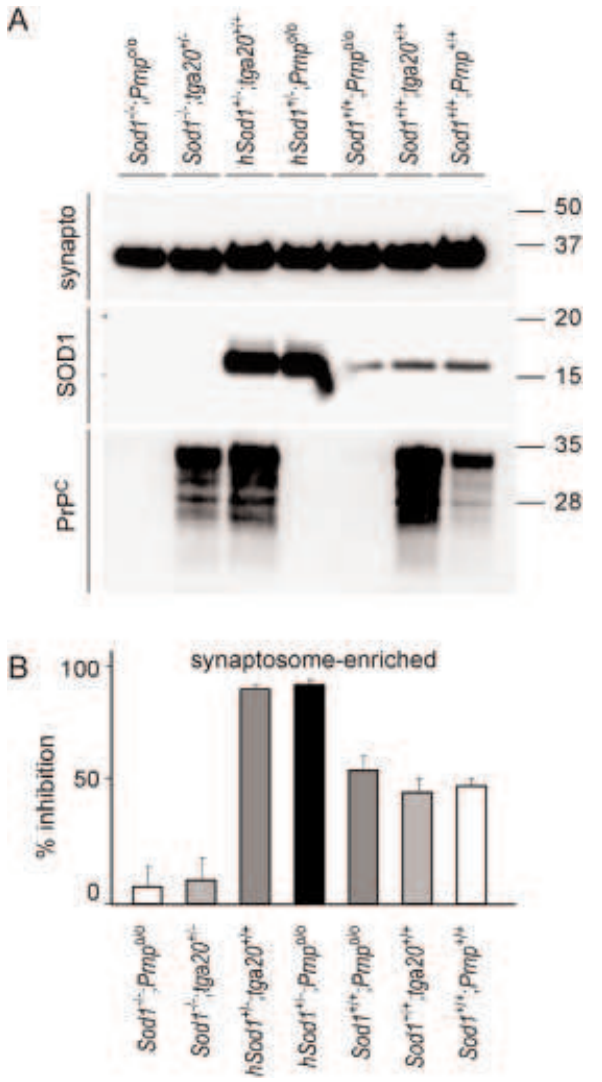

Fig. 4 Protein Expression and SOD Activity in SynaptosomeEnriched Brain Fractions.

(A) Western blot analysis of crude synaptosomal brain fractions of mouse genotypes, as indicated, consisting of synaptophysinpositive material (synapto, upper panel) displaying SOD1- and $\mathrm{PrPC}^{\mathrm{C}}$-protein in the respective samples. (B) Same samples as depicted in (A) were subjected to WST-formazan reduction in a xanthine-xanthine oxidase based SOD-assay with an endpoint measurement at $450 \mathrm{~nm}$. Percent inhibition of WST-formazan reduction of crude synaptosomes is illustrated. Again, no contribution of PrPC to the overall SOD activity (lanes $5-7$ ), nor a SODlike activity of PrPc, even when overexpressed, was detectable in the absence of endogenous SOD1 (lanes 1-2). Synaptosomal fractions of mice overexpressing human SOD1 served as positive controls (lanes 2-3). Two independent experiments were performed of which one representative is displayed. Each experiment was performed in triplicate and mean value \pm standard deviation is depicted.

ed hamsters (Choi et al., 1998) and mice (Lee et al., 1999). In addition, we were also not able to detect any alteration of SOD1 protein levels in terminally scrapie-sick mouse brains (G.H., F.L.H. and A.A., unpublished observations).

The negative results reported here certainly do not negate a role for reactive oxygen species in prion pathogenesis. Oxidative stress may play a role in a variety of neurodegenerative diseases (Perry et al., 2002). It will therefore be interesting to test whether absence or overexpression of SOD1 alters susceptibility of mice to prion infection, and to assess the capability of mice lacking SOD1 to cope with oxidative stress in the presence or absence of $\mathrm{PrPC}$.

\section{Materials and Methods}

\section{Generation and Genotyping of Transgenic Mice}

Prnpo (Büeler et al., 1992) and tga20 mice (Fischer et al., 1996) were intercrossed with Sod1/- mice lacking the endogenous SOD1 protein (Ho et al., 1998; Figure 1A), or with transgenic hSod1 mice (Epstein et al., 1987) which overexpress the human SOD1 protein. The following genotypes were obtained and used

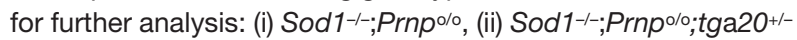

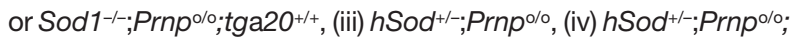
$\operatorname{tga} 20^{+/-}$or $h \mathrm{Sod}^{+/-} ; \mathrm{Prnp}^{\circ /} ; \operatorname{tga}^{2} \mathrm{O}^{+/+}$. As controls, the following littermates were used: (v) Sod $1^{+/+} ;$Prnp $^{\circ}$, (vi) Sod $1^{+/+} ;$Prnp $^{+/+}$and (vii) Sod1 ${ }^{+/+} ;$Prnpo/o;tga20+/+.

All genotypes were confirmed by PCR analysis of tail DNA (Figure 1B-D). The following primers were used: Detection of the $P_{r n p}{ }^{+}$and $P r n p^{\circ}$ alleles using 3 primers within the same PCR reaction as described (Fischer et al., 1996): (5' ATT CGC AGC GCA TCG CCT TCT ATC GCC 3'), (5' GTA CCC ATA ATC AGT GGA ACA AGC CCA GC 3'), (5' CCC TCC CCC AGC CTA GAC CAC GA 3'). Detection of the transgenic tga20+ allele: (5' CAA CCG AGC TGA AGC ATT CTG CCT 3'), (5' CCT GGG ACT CCT TCT GGT ACC GGG TGA CGC 3'). Detection of the transgenic $h$ Sod1 allele: (5' TGG GTA TTG TTG GGA GGA GG 3'), (5' TCT GTT CCA CTG AAG CTG TT 3'). Detection of the Sod+ allele by amplifying exon 5 of the murine Sod1-locus which is removed in the Sod1 $1^{-/}$ mice by targeted disruption (Ho et al., 1998): (5' CTT GAT CAT TCA AAC CTA AAT GTT CTT 3'), (5' CAG TTG AGT CTG AGA CTT CAG ACC ACA $3^{\prime}$ ). Detection of the Sod- allele by amplifying the exon 4/neo cassette in Sod1-/- mice (Ho et al., 1998): (5' GAA CAT CGT GTG ATC TCA CTC TCA GGA GAG 3'), (5' AAA AGC GCC TCC CCT ACC CGG TAG AAT TGA 3').

\section{Non-Denaturing Gel-Electrophoresis and SOD Zymography}

To confirm functionally the presence or absence of endogenous $\mathrm{SOD}$ and/or transgenic human $\mathrm{Cu}^{2+} / \mathrm{Zn}^{2+}$-superoxide dismutase (hSOD1) activity, erythrocytes were subjected to non-denaturing gel-electrophoresis as described (Beauchamp and Fridovich, 1971). Erythrocytes were lysed, loaded on a non-denaturing gel, and electrophoresed. Gels were stained with $1 \mathrm{mg} / \mathrm{ml}$ nitro-blue tetrazolium (NBT) for $20 \mathrm{~min}$ and thereafter soaked in $0.036 \mathrm{M}$ potassium phosphate buffer (all reagents were purchased from Sigma Inc., Buchs, Switzerland, unless otherwise specified), $\mathrm{pH} 7.8$, containing $10 \mu \mathrm{g} / \mathrm{ml}$ riboflavin and $3 \mu \mathrm{l} / \mathrm{ml}$ TEMED. Generation of superoxide radicals was induced by subjecting the gels to ultraviolet light resulting in reduction of NBT. Areas with SOD activity remained unstained due to superoxide dismutation (Figure 2A).

\section{Histological Analysis}

Mice were deeply anaesthetized, and brain, heart, liver and spleen were removed and fixed in 4\% paraformaldehyde in PBS. After embedding the organs in paraffin, tissue was processed according to standard procedures and routinely stained with hematoxylin and eosin (H\&E; data not shown).

\section{Preparation of Synaptosome-Enriched Brain Fractions}

Synaptosome-enriched brain fractions were prepared according to a protocol provided by Dr. Lloyd Vaughan (Veterinary Pathology, University of Zürich, Zürich, Switzerland). Mice were deeply anaesthetized and brains were removed. Next, brain tissue was cut into small pieces with a razor blade and homogenized by a teflon/glass homogenizer (12 strokes) in 10 volumes of ice-cold buffered sucrose (320 mm sucrose, 4 mM HEPES, pH 7.4) supplemented with a protease inhibitor cocktail ( 1 tablet per $10 \mathrm{ml}$ 
homogenate; Roche, Rotkreuz, Switzerland). Thereafter, homogenates were centrifuged for $10 \mathrm{~min}$ at $1100 \mathrm{~g}$ at $4^{\circ} \mathrm{C}$. Supernatant was transferred to a new tube and centrifuged for $15 \mathrm{~min}$ at $9200 \mathrm{~g}$ at $4{ }^{\circ} \mathrm{C}$ for a second time. The pellet was resuspended in $10 \mathrm{ml}$ ice-cold buffered sucrose and centrifuged once more for $15 \mathrm{~min}$ at $10500 \mathrm{~g}$ at $4^{\circ} \mathrm{C}$. The resulting pellet consisting of crude synaptosomes was then used for Western blot analysis or for SOD assays.

\section{SOD Assays}

Mice were deeply anaesthetized and perfused with ice-cold PBS $(\mathrm{pH} 7.4)$ in order to remove blood cells. Brain, liver, spleen and heart were excised, snap-frozen in liquid nitrogen, and stored at $-80^{\circ} \mathrm{C}$ until further use. Samples were weighed and thawed in ice-cold $50 \mathrm{~mm}$ phosphate buffer $(\mathrm{pH}$ 7.4) containing a proteinase inhibitor cocktail (1 tablet per $10 \mathrm{ml}$ homogenate; Roche). Samples were homogenized with a Polytron tissue grinder, and crude homogenates were centrifuged at $15000 \mathrm{~g}$ for $30 \mathrm{~min}$ at $4^{\circ} \mathrm{C}$. Supernatant was then analyzed by a standard BCA assay (Pierce, Rockford, USA) to determine protein concentration. All samples were then adjusted to the same concentration.

Three different SOD assays were used to analyze SOD and SOD-mimetic activity: First, a xanthine/xanthine-oxidase based assay (Dojindo Molecular Technologies) was performed according to the manufacturer's instruction. This assay utilizes the sodium salt of 4-[3-(4iodophenyl)-2-(4-nitrophenyl)-2H-5-tetrazolio]1,3-benzene disulfonate, a water-soluble tetrazolium (WST), as a detector of superoxide radical generation (Peskin and Winterbourn, 2000). The assay was standardized by measuring SOD activity of bovine erythrocytes (data not shown). Selective inhibition of SOD1 activity in Sod1+/+-Prnp ${ }^{+/+}$mice was achieved by adding $15 \mathrm{~mm}$ potassium cyanide (KCN) for $30 \mathrm{~min}$ on ice, thus allowing to assess the activity of the manganese SOD (MnSOD or SOD2). Lower doses of $\mathrm{KCN}$, in contrast to other reports (Okado-Matsumoto and Fridovich, 2001), did not result in complete inhibition of SOD1 in our experimental series. Two $\mu \mathrm{g}$ of total protein were analyzed per reaction; experiments were run in triplicates and analyzed in a 96-well plate reader (SpectraMax, Molecular Devices Corporation, Sunnyvale, USA). Upon application of the enzyme solution, the linear increase of absorption at $450 \mathrm{~nm}$ was monitored constantly over $30 \mathrm{~min}$ in kinetic or endpoint mode at $37^{\circ} \mathrm{C}$. Inhibition of formazan production was plotted against corresponding blank controls.

The second SOD assay is based on the SOD-mediated increase in the rate of autoxidation of $5,6,6 \mathrm{a}, 11 \mathrm{~b}$-tetrahydro3,9,10-trihydroxybenzo[c]fluorene in aqueous alkaline solution, which generates a chromophore with a wavelength of maximal absorbance at $525 \mathrm{~nm}$ (Nebot et al., 1993). The assay was performed according to the instructions of the manufacturer (Calbiochem, San Diego, USA). Tissue extracts were prepared as described above, and $250 \mu \mathrm{l}$ homogenate with a concentration of $5 \mu \mathrm{g} / \mu \mathrm{l}$ of total protein were subjected to ethanol/chloroform $(67.5 / 32.5 \mathrm{v} / \mathrm{v})$ extraction. Thereafter, $40 \mu \mathrm{l}$ of supernatant were incubated with the assay reagents as described according to the manufacturer's instructions. Absorption at $525 \mathrm{~nm}$ and $37^{\circ} \mathrm{C}$ was monitored for $5 \mathrm{~min}$. Increase of absorption per time of different samples in the linear range of the assay was plotted. All kinetic and endpoint data were processed automatically by the SOFTMax Pro software (SpectraMax).

Thirdly, we attempted to establish an NBT-based assay using the non-enzymatic superoxide generator phenazine methosulfate in combination with NADH (Ewing and Janero, 1995). Samples were prepared as described above. Additionally, sonication of the extract and/or treatment with $0.5 \% \mathrm{DOC}$ and $0.5 \% \mathrm{NP}-40$ followed by ultracentrifugation (78 $000 \mathrm{~g}, 30 \mathrm{~min}$ ) was performed. However, we experienced poor reproducibility and variability in repeated measurements of the same probes; therefore this assay was excluded from further analyses.

\section{Western Blots}

Aliquots of the same tissue homogenates as used for SOD assays were run on SDS-PAGE gels ( $5 \%$ stacking and $16 \%$ resolving) and transferred on nitrocellulose (Schleicher \& Schuell, Dassel, Germany) by wet blotting. Membranes were blocked with $5 \%$ Top-Block (Juro, Luzern, Switzerland) in Tris-buffered salineTween (TBS-T) at room temperature (RT) for 1 hour and, thereafter, incubated for one hour at RT with the primary antibody diluted in 1\% Top-Block in TBS-T. As primary antibody we used an anti-PrP antibody (ICSM18; kind gift of Dr. S. Hawke, London, UK; dilution 1:30 000), an anti-SOD1 antibody (Calbiochem; dilution 1:1 000: approximately $16 \mathrm{kDa}$ ), an anti-SOD2 antibody (Stressgen, Victoria, Canada; dilution 1:5 000; approx. $25 \mathrm{KDa}$ ) or an anti- $\beta$-actin antibody (Jackson, USA; dilution 1: 5 000). Membranes were washed three times for $15 \mathrm{~min}$ in TBS-T, and incubated for further 45 minutes with a horseradish peroxidase (HRP)-labeled secondary antibody diluted in 1\% Top-Block in TBS-T. As secondary antibody we used rabbit-anti-mouse $\lg _{1}$ HRP (Zymed, South San Francisco, USA, dilution 1:10 000) for detecting anti-PrP and anti- $\beta$-actin antibodies or goat-antisheep IgG-HRP for detecting anti-SOD1 and anti-SOD2 antibodies (Jackson; dilution 1:10 000). Membranes were washed three times for $15 \mathrm{~min}$ in TBS-T and developed using enhanced chemiluminescence (ECL, Pierce) detection reagents.

\section{Acknowledgments}

We would like to thank Dr. Ye-Shi Ho (Wayne State University, USA) and Dr. Charles J. Epstein (University of California, USA) for kindly providing Sod $1^{-/-}$and transgenic $h$ Sod 1 mice as well as for helpful advice and Denis Marino and Petra Schwarz for excellent technical assistance. Supported by grants of the Bundesamt für Bildung und Wissenschaft, the NCCR-Neuro, and the Swiss National Foundation to A.A. as well as the Bonizzi-Theler and Stammbach foundation to F.L.H.

\section{References}

Basler, K., Oesch, B., Scott, M., Westaway, D., Walchli, M., Groth, D.F., McKinley, M. P., Prusiner, S.B., and Weissmann, C. (1986). Scrapie and cellular PrP isoforms are encoded by the same chromosomal gene. Cell 46, 417-428.

Beauchamp, C., and Fridovich, I. (1971). Superoxide dismutase: improved assays and an assay applicable to acrylamide gels. Anal. Biochem. 44, 276-287.

Behrens, A., and Aguzzi, A. (2002). Small is not beautiful: antagonizing functions for the prion protein $\operatorname{PrP}(\mathrm{C})$ and its homologue Dpl. Trends Neurosci. 25, 150-154.

Brown, D.R., and Besinger, A. (1998). Prion protein expression and superoxide dismutase activity. Biochem. J. 334, 423429.

Brown, D.R., Nicholas, R.S., and Canevari, L. (2002). Lack of prion protein expression results in a neuronal phenotype sensitive to stress. J. Neurosci. Res. 67, 211-224.

Brown, D.R., Qin, K., Herms, J.W., Madlung, A., Manson, J., Strome, R., Fraser, P.E., Kruck, T., von Bohlen, A., SchulzSchaeffer, W., et al. (1997a). The cellular prion protein binds copper in vivo. Nature 390, 684-687. 
Brown, D.R., Schulz-Schaeffer, W.J., Schmidt, B., and Kretzschmar, H.A. (1997b). Prion protein-deficient cells show altered response to oxidative stress due to decreased SOD-1 activity. Exp. Neurol. 146, 104-112.

Brown, D.R., Schmidt, B., and Kretzschmar, H.A. (1998). Effects of copper on survival of prion protein knockout neurons and glia. J. Neurochem. 70, 1686-1693.

Brown, D.R., Wong, B.S., Hafiz, F., Clive, C., Haswell, S.J., and Jones, I.M. (1999). Normal prion protein has an activity like that of superoxide dismutase [published erratum: (2000) Biochem. J. 345, 767]. Biochem. J. 344, 1-5.

Büeler, H.R., Aguzzi, A., Sailer, A., Greiner, R.A., Autenried, P., Aguet, M., and Weissmann, C. (1993). Mice devoid of PrP are resistant to scrapie. Cell 73, 1339-1347.

Büeler, H.R., Fischer, M., Lang, Y., Bluethmann, H., Lipp, H.P., DeArmond, S.J., Prusiner, S.B., Aguet, M., and Weissmann, C. (1992). Normal development and behaviour of mice lacking the neuronal cell-surface PrP protein. Nature 356, 577-582.

Choi, S.I., Ju, W.K., Choi, E.K., Kim, J., Lea, H.Z., Carp, R.I., Wisniewski, H.M., and Kim, Y.S. (1998). Mitochondrial dysfunction induced by oxidative stress in the brains of hamsters infected with the $263 \mathrm{~K}$ scrapie agent. Acta Neuropathol. 96, 279-286.

Epstein, C.J., Avraham, K.B., Lovett, M., Smith, S., Elroy-Stein, O., Rotman, G., Bry, C., and Groner, Y. (1987). Transgenic mice with increased $\mathrm{Cu} / \mathrm{Zn}$-superoxide dismutase activity: animal model of dosage effects in Down syndrome. Proc. Natl. Acad. Sci. USA 84, 8044-8048.

Ewing, J.F., and Janero, D.R. (1995). Microplate superoxide dismutase assay employing a nonenzymatic superoxide generator. Anal. Biochem. 232, 243-248.

Fischer, M., Rülicke, T., Raeber, A., Sailer, A., Moser, M., Oesch, B., Brandner, S., Aguzzi, A., and Weissmann, C. (1996). Prion protein $(\operatorname{PrP})$ with amino-proximal deletions restoring susceptibility of PrP knockout mice to scrapie. EMBO J. 15, 1255-1264.

Ho, Y.S., Gargano, M., Cao, J., Bronson, R.T., Heimler, I., and Hutz, R.J. (1998). Reduced fertility in female mice lacking copper-zinc superoxide dismutase. J. Biol. Chem. 273, 77657769.

Hornshaw, M.P., McDermott, J.R., Candy, J.M., and Lakey, J.H. (1995). Copper binding to the $\mathrm{N}$-terminal tandem repeat region of mammalian and avian prion protein: structural studies using synthetic peptides. Biochem. Biophys. Res. Commun. 214, 993-999.

Kira, Y., Sato, E.F., and Inoue, M. (2002). Association of Cu,Zntype superoxide dismutase with mitochondria and peroxisomes. Arch. Biochem. Biophys. 399, 96-102.

Klamt, F., Dal-Pizzol, F., Conte da Frota, M. J., Walz, R., Andrades, M.E., da Silva, E.G., Brentani, R.R., Izquierdo, I., and Fonseca Moreira, J.C. (2001). Imbalance of antioxidant defense in mice lacking cellular prion protein. Free Radic. Biol. Med. 30, 1137-1144.

Kretzschmar, H.A., Tings, T., Madlung, A., Giese, A., and Herms, J. (2000). Function of $\operatorname{PrP}(C)$ as a copper-binding protein at the synapse. Arch. Virol. Suppl. 16, 239-249.

Kuwahara, C., Takeuchi, A.M., Nishimura, T., Haraguchi, K., Kubosaki, A., Matsumoto, Y., Saeki, K., Yokoyama, T., Itohara, S., and Onodera, T. (1999). Prions prevent neuronal cell-line death. Nature 400, 225-226.

Lee, D.W., Sohn, H.O., Lim, H.B., Lee, Y.G., Kim, Y.S., Carp, R.I., and Wisniewski, H.M. (1999). Alteration of free radical metabolism in the brain of mice infected with scrapie agent. Free Radic. Res. 30, 499-507.

Milhavet, O., and Lehmann, S. (2002). Oxidative stress and the prion protein in transmissible spongiform encephalopathies. Brain Res. Brain Res. Rev. 38, 328-339.

Milhavet, O., McMahon, H.E., Rachidi, W., Nishida, N., Katamine, S., Mange, A., Arlotto, M., Casanova, D., Riondel, J., Favier, A., and Lehmann, S. (2000). Prion infection impairs the cellular response to oxidative stress. Proc. Natl. Acad. Sci. USA 97, $13937-13942$.

Moore, R.C., Lee, I.Y., Silverman, G.L., Harrison, P.M., Strome, R., Heinrich, C., Karunaratne, A., Pasternak, S.H., Chishti, M.A., Liang, Y. et al. (1999). Ataxia in prion protein (PrP)-deficient mice is associated with upregulation of the novel PrPlike protein doppel. J. Mol. Biol. 292, 797-817.

Nebot, C., Moutet, M., Huet, P., Xu, J.Z., Yadan, J.C., and Chaudiere, J. (1993). Spectrophotometric assay of superoxide dismutase activity based on the activated autoxidation of a tetracyclic catechol. Anal. Biochem. 214, 442-451.

Oesch, B., Westaway, D., Walchli, M., McKinley, M.P., Kent, S.B., Aebersold, R., Barry, R.A., Tempst, P., Teplow, D.B., Hood, L.E., and Weissmann, C. (1985). A cellular gene encodes scrapie PrP 27-30 protein. Cell 40, 735-746.

Okado-Matsumoto, A., and Fridovich, I. (2001). Assay of superoxide dismutase: cautions relevant to the use of cytochrome c, a sulfonated tetrazolium, and cyanide. Anal. Biochem. 298, $337-342$.

Perry, G., Nunomura, A., Hirai, K., Zhu, X., Prez, M., Avila, J., Castellani, R.J., Atwood, C.S., Aliev, G., Sayre, L.M., et al. (2002). Is oxidative damage the fundamental pathogenic mechanism of Alzheimer's and other neurodegenerative diseases? Free Radic. Biol. Med. 33, 1475-1479.

Peskin, A. V., and Winterbourn, C. C. (2000). A microtiter plate assay for superoxide dismutase using a water-soluble tetrazolium salt (WST-1). Clin. Chim. Acta 293, 157-166.

Prusiner, S.B. (1982). Novel proteinaceous infectious particles cause scrapie. Science 216, 136-144.

Sayre, L.M., Perry, G., and Smith, M.A. (1999). Redox metals and neurodegenerative disease. Curr. Opin. Chem. Biol. 3, 220225.

Stockel, J., Safar, J., Wallace, A.C., Cohen, F.E., and Prusiner, S.B. (1998). Prion protein selectively binds copper(II) ions. Biochemistry 37, 7185-7193.

Ukeda, H., Maeda, S., Ishii, T., and Sawamura, M. (1997). Spectrophotometric assay for superoxide dismutase based on tetrazolium salt 3'-1-(phenylamino)-carbonyl-3, 4-tetrazolium]-bis(4-methoxy-6-nitro)benzenesulfonic acid hydrate reduction by xanthine-xanthine oxidase. Anal. Biochem. 251, 206-209.

Waggoner, D.J., Drisaldi, B., Bartnikas, T.B., Casareno, R.L., Prohaska, J.R., Gitlin, J.D., and Harris, D.A. (2000). Brain Copper Content and Cuproenzyme Activity Do Not Vary with Prion Protein Expression Level. J. Biol. Chem. 275, 7455-7458.

Wong, B.S., Liu, T., Li, R., Pan, T., Petersen, R.B., Smith, M.A., Gambetti, P., Perry, G., Manson, J.C., Brown, D.R., and Sy, M.S. (2001). Increased levels of oxidative stress markers detected in the brains of mice devoid of prion protein. J. Neurochem. 76, 565-572.

Wong, B.S., Pan, T., Liu, T., Li, R., Gambetti, P., and Sy, M.S. (2000). Differential contribution of superoxide dismutase activity by prion protein in vivo. Biochem. Biophys. Res. Commun. 273, 136-139.

Wong, B.S., Wang, H., Brown, D.R., and Jones, I.M. (1999). Selective oxidation of methionine residues in prion proteins. Biochem. Biophys. Res. Commun. 259, 352-355.

Received May 26, 2003; accepted June 23, 2003 